\title{
Spontaneous pregnancy at term with uterus didelphys: a case report
}

\author{
Romuald Randriamahavonjy ${ }^{1}$, Tanjona A. Ratsiatosika ${ }^{2 *}$, Sidy Fleurian ${ }^{2}$, Housni IA ${ }^{2}$, Todisoa \\ M. Rakotomboahangy ${ }^{3}$, Rasoanandrianina B. Solange ${ }^{4}$, Hery R. Andrianampanalinarivo ${ }^{4}$
}

\author{
${ }^{1}$ Department of Obstetrics and Gynecology, Soavinandriana Hospital Center, Antananarivo, Madagascar \\ ${ }^{2}$ Department of Public Health, Faculty of Medicine Antananarivo, Antananarivo, Madagascar \\ ${ }^{3}$ Department of Obstetrics and Gynecology, Faculty of Medicine, Antsiranana, Madagascar \\ ${ }^{4}$ Department of Obstetrics and Gynecology, Faculty of Medicine Antananarivo, Antananarivo, Madagascar
}

\author{
Received: 25 July 2018 \\ Accepted: 28 August 2018 \\ *Correspondence: \\ Dr. Tanjona A. Ratsiatosika, \\ E-mail: ratsiatosika.tanjona@gmail.com
}

Copyright: (C) the author(s), publisher and licensee Medip Academy. This is an open-access article distributed under the terms of the Creative Commons Attribution Non-Commercial License, which permits unrestricted non-commercial use, distribution, and reproduction in any medium, provided the original work is properly cited.

\begin{abstract}
The uterus didelphys results from the absence of fusion of the bilateral mullerian ducts. It is a rare pathology. This malformation concerns $5 \%$ of uterine malformations from mullerian ducts and affects one woman in 1,000-30,000. Obstetrical complications of this malformation are numerous. The chance of reaching term for pregnancies with didelphys uterus is reported as $20 \%-30 \%$. Authors report a case of spontaneous term pregnancy in a 21-year-old primiparous woman with a didelphic uterus. The patient had an unexplained seizure with fetal bradycardia. An emergency cesarean section was performed and allowed the birth of a hypotropic neonate of $2240 \mathrm{~g}$ and the discovery of didelphic uterus. Pregnancy developed in the left hemi-uterus. Speculum examination at the end of the procedure showed a longitudinal vaginal septum. There was no associated urinary tract and renal malformation. Scheduled cesarean will be performed from her next pregnancy. The uterus didelphys should be diagnosed early. MRI and 3D echography are necessary for diagnosis. Pregnancy is often complicated, and follow-up needs to be planned. Cesarean section is not systematic.
\end{abstract}

Keywords: Delivery, Pregnancy, Uterine didelphys, Uterine malformation

\section{INTRODUCTION}

The uterus didelphys results from the absence of fusion of the two Mullerian ducts. ${ }^{1}$ Both ducts evolve into two separate hemi uteri. Other structures are also separated, ovaries, fallopian tubes, and cervix. The vagina can be single or double. ${ }^{2}$

This malformation concerns $5 \%$ of uterine malformations from mullerian ducts and affects one woman in 1,000$30,000 .^{3,4}$ Congenital uterine malformation is frequently asymptomatic. The vaginal septum may cause dyspareunia, leucorrhea, dysmenorrhea if it is completely obstructed. ${ }^{4}$ Pregnancy anomalies or infertility may lead to the diagnosis. Transvaginal ultrasonography is very useful for the diagnosis. But MRI becomes the first exam to confirm it. $^{2}$ The uterus didelphys may be identified during caesarean section.

This malformation is associated with a renal malformation in $30 \%$ of the cases. ${ }^{5}$ Pregnancy complications with uterus didelphys are numerous such as abortion, malpresentation, premature rupture of membrane, intrauterine growth restriction and preterm birth. ${ }^{2}$ The chance of reaching term for pregnancies with didelphys uterus is reported as $20 \%-30 \%$. $^{2}$ Through this 
presentation, we report a case of pregnancy reaching term on uterus didelphys discovered during an emergency Caesarean section.

\section{CASE REPORT}

It is about a 21-year-old patient, primigravida, admitted in obstetric emergency departments for unexplained generalized tonic-clonic seizures, at 39 weeks of Amenorrhea and five days. The pregnancy was spontaneous and normal evolution until then. The patient had no history of high blood pressure or epilepsy. The disease is summarized by the appearance of a generalized tonic-clonic convulsive seizure without prodrome followed by a loss of urine, drooling and post-critical unconsciousness of about one minute, which motivates its consultation. During examination, the blood pressure was $110 / 60 \mathrm{mmHg}$, the heart rate was 60 beats / min. She was afebrile. The patient was conscious. She complained of moderate headache. The neurological examination was normal. There was no recurrence of the convulsion. Proteinuria was absent in the urine dipstick. There was no uterine contraction. The fetal cardiotocography had shown fetal bradycardia at 100 beats per minute. An emergency cesarean section was performed for fetal bradycardia.

The surgical intervention was performed under general anesthesia. A segmental hysterotomy was performed. The extraction was difficult and allowed the birth of a $2240 \mathrm{~g}$ male newborn with intrauterine growth restriction. The Apgar score in the fifth minute was 9. The deliverance was normal. At the exteriorization of the uterus outside the peritoneal cavity, we discovered a uterus didelphys (Figure 1).

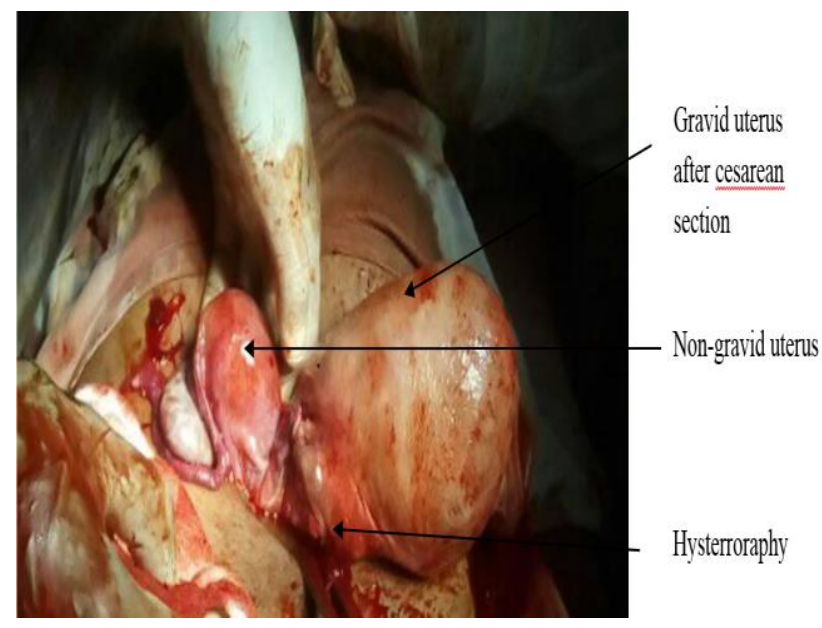

Figure 1: Didelphic uterus after caesarean section

Pregnancy developed in the left hemi-uterus. The hysterorraphy was without particularity. Examination of the vagina at the end of the procedure showed a longitudinal septum with two vaginas and two cervix (Figure 2). The operative sequence was normal. She came out of the hospital on the fifth day. There is no recurrence of the convulsive seizure and the neurological examinations performed were normal. The patient was seen one month after the procedure. There was no neurological abnormality. Echography of the urinary tract and kidney was normal. Scheduled cesarean will be performed from her next pregnancy.

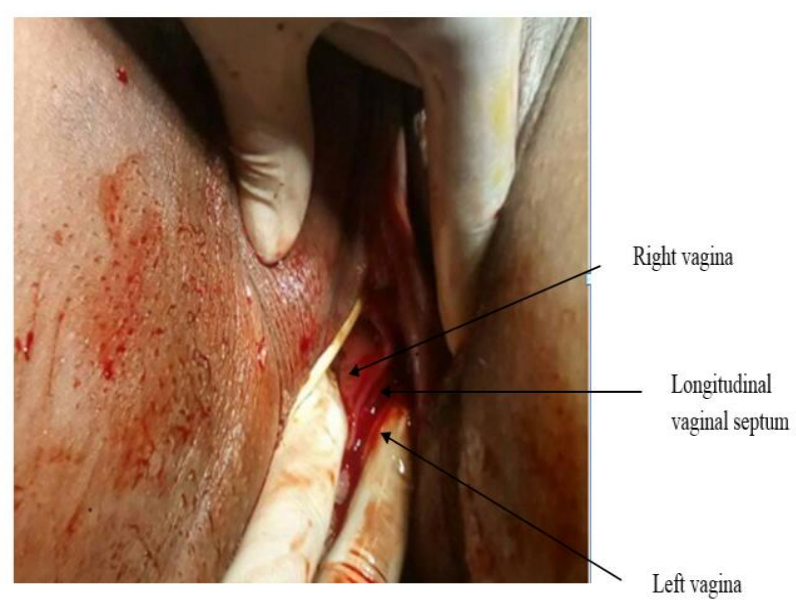

Figure 2: Vaginal examination showing the vaginal septum.

\section{DISCUSSION}

The uterus didelphys (type III according to the American Fertility Society's classification: AFS) corresponds to two completely separate hemi-uterus with two cervix. ${ }^{6}$ The horns can be asymmetrical. It results from a fusion failure of the mullerian ducts. It develops at the $10^{\text {th }}-13^{\text {th }}$ week of embryonic development. Diagnosis is suspected by clinical signs (amenorrhea, dysmenorrhea, infertility, repeated miscarriage, premature delivery). Imaging exams confirm the diagnosis. Hysterography is no longer the first-line examination. 3D echography remains very useful, but MRI remains the gold standard in the exploration of pelvic malformations. ${ }^{5}$ In our context, the patient did not receive one of these exams. The diagnosis was made only intraoperatively.

Regarding the outcome of pregnancy in patients with didelphic uterus, Heinonen reported a $30 \%$ of miscarriage, $43 \%$ of malpresentation, and $82 \%$ of cesarean section and $11 \%$ of small for gestational age. ${ }^{4}$ According to Chan and al, Patients with uterus didelphys had a preterm birth risk of 3.58 times higher $(95 \% \mathrm{CI}=$ 2.00-6.40), with a 3.7-fold increase in malpresentation (95\% CI=2.04-6.70). By contrast, the risk of miscarriage is identical. ${ }^{7}$ For our case, the pregnancy was reached term but was complicated by a neonatal hypotrophy. Convulsion alone does not explain the low birth weight.

Delivery is most often done by cesarean section. ${ }^{4}$ An anomaly of the presentation is observed. Most often, the fetus is in breech presentation. ${ }^{4,7,8}$ Mechanical obstructed labor may also occur. The hemi-uterus is sometimes a 
previa obstacle. ${ }^{9,10}$ However, normal deliveries have been reported even in cases of vaginal septum. ${ }^{11}$

In our case, the delivery route will be a cesarean section scheduled for the next pregnancy. Indeed, in our practice, a history of previous Cesarean section associated with a uterine malformation is an indication of cesarean section. In the literature, the risk of uterine rupture in patients with non-scarring uterus was 1: $15,000 .{ }^{12}$ In addition, a study has shown that the risk of uterine rupture in patients with a uterine malformation of Mullerian origin is identical to the general population. ${ }^{13}$ But vaginal delivery is rare in these patients. ${ }^{4}$ The frequency of cesarean section rises to $69.2 \% .^{13}$

There was no renal malformation in our patient. In the literature, a didelphic uterus is often associated with a renal malformation. In 20 to $30 \%$ of the cases, the renal malformation is presented. ${ }^{14}$ This can be an agenesis, an ectopia, or a malrotation. A systematic study of the kidneys must be performed when a uterine malformation is discovered. This is part of a malformation assessment. ${ }^{5}$ The MRI is useful to identify these malformations. ${ }^{5,15}$

\section{CONCLUSION}

To conclude, the frequency of the uterus didelphys is rare. The diagnosis must be precocious. MRI and 3D echography are of particular interest for diagnosis. Once diagnosed, follow-up should be closely and regularly as complications are numerous. The delivery route depends on the presentation of the fetus and the occurrence of a previa obstacle by the hemi-uterus during labor. Cesarean section is not systematic.

\section{Funding: No funding sources}

Conflict of interest: None declared

Ethical approval: Not required

\section{REFERENCES}

1. Grimbizis GF, Camus M, Tarlatzis BC, Bontis JN, Devroey P. Clinical implications of uterine malformations and hysteroscopic treatment results. Hum Reprod Update. 2001;7(2):161-74.

2. Öndeş B. $8^{\text {th }}$ Term pregnancy in uterus didelphys: a rare case report. Case Reports Perinatal Med. 2017;6(1).

3. Troiano RN, McCarthy SM. Mullerian duct anomalies: imaging and clinical issues. Radiol. 2004;233(1):19-34.

4. Heinonen PK. Uterus didelphys: a report of 26 cases. European J Obstet Gynecol. 1984;17(5):345-50.
5. Mordefroid M, Levaillant JM. Malformations utérines: utérus bicorne ou cloisonné?: Critères de différenciation en IRM et échographie 3D. Imagerie de la Femme. 2008;18(2):89-100.

6. Musset R, Muller P, Netter A, Solal R. Necessity for a global classification of uterine malformations. Associated urinary malformations. Interest of certain peculiarities in the light of 141 cases. Gynecologie Obstet. 1967;66(2):145-66.

7. Chan YY, Jayaprakasan K, Tan A, Thornton JG, Coomarasamy A, Raine-Fenning NJ. Reproductive outcomes in women with congenital uterine anomalies: a systematic review. Ultrasound Obstet Gynecol. 2011;38(4):371-82.

8. Felker EA. Uterus Didelphys and Pregnancy. J Diag Med Sonograp. 2004; 20(2):131-33

9. Muller P, Barrat J. Pregnancy and delivery in cases of uterine malformations. In, Roger Vokaer, obstetrics treatise. Ed, Masson Paris, 1985;II:458-71.

10. N'Gbesso RD, Ouedrago S, Quenum G, Ould-Beddi M, N'Goan-Domoua AM, Koné R. A rare etiology of an obstacle previa by non-uterine uterus (didelphe): contribution of ultrasound. J Radiol 2004;85:655-7.

11. Magudapath C. Uterus Didelphys with Longitudinal Vaginal Septum: Normal Delivery. J Clin Case Rep. 2012;2:194.

12. Altwerger G, Pritchard AM, Black JD, Sfakianaki A. Uterine Didelphys and Vaginal Birth After Cesarean Delivery. Obstet Gynecol 2015;125:157-9.

13. Erez O, Dukler D, Novack L, Rozen A, Zolotnik L, Bashiri A, et al. Trial of labor and vaginal birth after cesarean section in patients with uterine Müllerian anomalies: a population-based study. Am J Obstet Gynecol. 2007;196:537.1-11.

14. Green LK, Harris RE. Uterine anomalies; frequency of diagnosis and associated obstetrical complications. Obstet Gynecol. 1976;47:427-9.

15. Pellerito JS, McCarthy SM, Doyle MB, Glickman MG, DeCherney AH. Diagnosis of uterine anomalies: relative accuracy of MR imaging, endova ginal sonography and hysterosalpingography. Radiol. 1992;183(3):795-800.

Cite this article as: Randriamahavonjy $\mathrm{R}$,

Ratsiatosika TA, Fleurian S, Housni IA,

Rakotomboahangy TM, Solange RB, et al.

Spontaneous pregnancy at term with uterus didelphys: a case report. Int J Reprod Contracept

Obstet Gynecol 2018;7:4282-4. 